\title{
Coprodutos do óleo de soja na dieta de codornas: impactos sobre a qualidade durante o armazenamento
}

\author{
Soybean oil by-products in quail diets: impact on quality during storage
}

\author{
Caroline Bavaresco ${ }^{1 \star}$, Valmor Ziegler ${ }^{2}$, Débora Cristina Nichelle Lopes ${ }^{1}$, Moacir Cardoso Elias², \\ Eduardo Gonçalves Xavier ${ }^{1}$, Victor Fernando Büttow Roll ${ }^{1}$ \\ 1 Universidade Federal de Pelotas (UFPEL), Departamento de Zootecnia, Pelotas/RS - Brasil \\ 2 Universidade Federal de Pelotas (UFPEL), Departamento de Ciências e Tecnologia Agroindustrial, Pelotas/RS - Brasil
}

\section{*Corresponding Author}

Caroline Bavaresco, Universidade Federal de Pelotas (UFPEL), Departamento de Zootecnia, Campus Universitário Capão do Leão, s/n, CEP: $96010-900$, Pelotas/RS - Brasil, e-mail: carolinebavaresco@hotmail.com

Cite as: Soybean oil by-products in quail diets: impact on quality during storage. Braz. J. Food Technol., v. 21, e2016168, 2018.

Received: Dec. 01, 2016; Accepted: July 26, 2017

\section{Resumo}

O presente estudo teve por objetivo avaliar a influência do tempo de armazenamento $(0,15$ e 30 dias) sobre a degradabilidade de nutrientes em dietas formuladas com óleo ácido de soja, suplementadas ou não com lecitina. Oito dietas experimentais foram avaliadas: 1) dieta basal (DB) com $4 \%$ de óleo ácido de soja (OAS); 2) DB com 4\% OAS + 1\% lecitina (LEC); 3) DB com 8\% OAS; 4) DB com 8\% OAS + 1\% LEC; 5) DB com 4\% de óleo degomado de soja (ODS); 6) DB com $4 \%$ ODS + 1\% LEC; 7) DB com 8\% ODS; 8) DB com 8\% ODS + 1\% LEC. Foram coletadas seis amostras de cada dieta para medir a degradabilidade de nutrientes no início, aos 15 e 30 dias de armazenamento. Foram avaliadas a composição química (matéria seca, proteína bruta e extrato etéreo), a acidez livre e o coeficiente de extinção específica ( $K$ e $K$ ), em todas as dietas. O tempo de armazenamento influenciou o conteúdo de matéria seca, sendo que o tempo zero apresentou as menores médias para os tratamentos 3, 4 e 5. Foi observada interação significativa entre os fatores dieta e tempo, para as variáveis de acidez e coeficientes de extinção. Dietas com óleo ácido de soja apresentaram maior acidez e mais produtos primários e secundários da oxidação do que dietas com óleo degomado de soja. A proteína bruta e o extrato etéreo não foram afetados pelo tempo de armazenamento, em todas as dietas.

Palavras-chave: Dietas; Acidez; Oxidação.

\section{Abstract}

This study aimed to evaluate the effect of storage time (0,15 and 30 days) on the degradability of nutrients in quail diets formulated with acidulated soybean oil supplemented or not with lecithin. Eight experimental diets were evaluated: 1) basal diet (BD) with $4 \%$ acidulated soybean oil (ASS); 2) BD with 4\% ASS + 1\% lecithin (LEC); 3) BD with $8 \%$ ASS; 4) BD with $8 \%$ ASS + $1 \%$ LEC; 5) BD with $4 \%$ degummed soybean oil (DSO); 6) BD with $4 \%$ DSO + 1\% LEC; 7 ) BD with $8 \%$ DSO; 8 ) BD with $8 \%$ DSO $+1 \%$ LEC. Six samples of each diet were collected to assess the degradability of nutrients on zero day and after 15 and 30 days of storage. The chemical composition (dry matter, crude protein and fat), free acidity and specific extinction coefficients ( $K$ and $K$ ) in all diets were evaluated. The storage time influenced the dry matter content, and zero time presented the lowest averages for treatments 3, 4 and 5. A significant interaction between the diet and the time factors was observed for the acidity variables and extinction coefficients. Diets with acidulated soybean oil showed higher acidity and primary and secondary peroxidation products than the degummed soybean oil diets. Crude protein and fat were not affected by storage time in any of the diets.

Keywords: Feed; Acidity; Peroxidation. 


\section{Introdução}

De acordo com estimativa da Associação Brasileira das Indústrias dos Óleos Vegetais (ABIOVE, 2016), o principal óleo utilizado para formulação de dietas na avicultura é o de soja. Durante o processo de refino do óleo de soja, na etapa de neutralização, é gerada uma borra. Essa borra é constituída basicamente de ácidos graxos livres e, por isso, denominada de óleo ácido. Este coproduto, também conhecido por soapstock, representa cerca de 2 a $3 \%$ do óleo de soja bruto (RABER et al., 2009). Levando-se em consideração que a capacidade brasileira de refino de óleo de soja em 2015 atingiu o montante de 8,07 milhões de toneladas de óleo de soja, estima-se uma produção de cerca de 222 toneladas de óleo ácido. Portanto, utilizar esse subproduto na dieta de aves pode ser uma alternativa como fonte energética para a complementação das exigências nutricionais desses animais, além de ser um fator em potencial para diminuir os custos de produção da atividade avícola.

Outro coproduto gerado durante o refino do óleo de soja é a lecitina (LEC), que é extraída na etapa de degomagem do óleo e é uma mistura de fosfatídeos (lecitina, cefalina e fosfatidil-inositol), 38\% de óleo e $2 \%$ de umidade (MANDARINO et al., 2015). Essas características da LEC conferem-Ihe a capacidade de emulsificar compostos, facilitando a formação de micelas e, assim, auxiliar na absorção de lipídeos e ácidos graxos.

Existem diversos benefícios ao adicionar óleo na dieta de aves, como: melhorar o aproveitamento de nutrientes pela redução da taxa de passagem, aumentar a absorção de vitaminas lipossolúveis, funcionar como aporte de ácidos graxos, entre outros. Contudo, deve haver uma preocupação com as reações de degradação, que são favorecidas pela adição de fontes lipídicas nas dietas, como é o caso da rancificação, que é agravada quando as rações são armazenadas.

Radicais livres provenientes da oxidação ou até mesmo da composição do alimento são altamente susceptíveis ao ataque do oxigênio atmosférico, formando os produtos primários de oxidação, como os peróxidos, hidroperóxidos e dienos conjugados, os quais são bastante instáveis e se degradam para formar os produtos secundários de oxidação, como cetonas, aldeídos e álcoois, ocasionando sabor e odor desagradáveis aos óleos e gorduras (CLODOVEO et al., 2007; RODRIGUES et al., 2012). Adicionalmente, a degradação dos triglicerídeos também pode ocorrer por hidrólise enzimática, resultando no ranço hidrolítico e acarretando, dessa forma, o aumento da acidez (NAZ et al., 2004).

Considerando-se os fatores descritos anteriormente, o objetivo deste trabalho foi avaliar o efeito da inclusão de coprodutos do refino do óleo de soja na dieta de codornas, avaliando a sua qualidade ao longo de 30 dias de armazenamento.

\section{Material e métodos}

\subsection{Avaliações}

Foram formuladas dietas para a nutrição de codornas japonesas com dois tipos de óleo de soja - ácido e degomado - em dois níveis de inclusão (4 e 8\%), e com a suplementação ou não de lecitina (0 e 1\%), obtendo-se as seguintes dietas experimentais: 1) dieta basal (DB) com 4\% de óleo ácido de soja (OAS); 2) DB com 4\% OAS + 1\% lecitina (LEC); 3) DB com 8\% OAS; 4) DB com 8\% OAS + 1\% LEC; 5) DB com 4\% de óleo degomado de soja (ODS); 6) DB com 4\% ODS + 1\% LEC; 7) DB com 8\% ODS; 8) DB com $8 \%$ ODS + 1\% LEC (Tabela 1). Todas as dietas apresentavam a mesma quantidade de energia metabolizável e proteína bruta em sua composição.

O OAS foi obtido a partir de uma indústria de refino de óleo de soja, pela separação da borra residual proveniente da etapa de neutralização. Essa borra foi tratada com ácido sulfúrico, dando origem ao OAS. A LEC e o ODS foram obtidos do mesmo fornecedor, sendo a LEC originada na etapa de degomagem do óleo de soja, sem haver nenhum processo de purificação desse material.

Os óleos utilizados nas dietas foram analisados pelo laboratório CBO em Campinas-SP, para determinação da acidez em ácido oleico, de acordo com a metodologia proposta pelo Compêndio Brasileiro de Alimentação Animal (SINDIRAÇÕES, 2005).

Cada dieta experimental foi acondicionada em dois baldes plásticos com tampa (capacidade de $18 \mathrm{~L}$ ), até 30 dias, em sala com temperatura mínima e máxima, respectivamente, de $16,5^{\circ} \mathrm{C} \pm 1,71$ e $18,7^{\circ} \mathrm{C} \pm 1,66$, e umidade relativa do ar mínima e máxima, respectivamente, de $65 \% \pm 9,96$ e 78,7\% $\pm 6,43$. Amostras das dietas experimentais foram coletadas em duplicata (uma amostra por balde), no início do armazenamento (zero dia), após 15 e 30 dias, em três preparos das rações.

\subsection{Métodos}

As amostras para avaliação da composição química aproximada foram homogeneizadas e encaminhadas para o Laboratório de Nutrição Animal (LNA), do Departamento de Zootecnia da Universidade Federal de Pelotas. O material foi processado em moinho laboratorial (Perten 3100, Perten Instruments, Huddinge, Sweden), para redução das partículas em 35 mesh. Todas as análises foram realizadas em duplicata.

O conteúdo de matéria seca (MS), proteína bruta (PB) e extrato etéreo (EE) foi determinado segundo metodologia da AOAC (HORWITZ, 2006). 
Tabela 1. Composição das dietas experimentais.

\begin{tabular}{|c|c|c|c|c|c|c|c|c|}
\hline \multirow{2}{*}{ Ingredientes (kg) } & \multicolumn{8}{|c|}{ Tratamentos $^{4}$} \\
\hline & T1 & T2 & T3 & T4 & T5 & T6 & T7 & T8 \\
\hline Milho & 42,60 & 40,68 & 32,37 & 30,36 & 41,50 & 39,53 & 30,08 & 28,14 \\
\hline Farelo de soja & 35,70 & 36,00 & 37,55 & 37,66 & 35,83 & 36,20 & 37,98 & 38,33 \\
\hline Inerte $^{1}$ & 6,35 & 6,97 & 10,71 & 11,36 & 7,31 & 7,92 & 12,62 & 13,21 \\
\hline Núcleo² & 5,00 & 5,00 & 5,00 & 5,00 & 5,00 & 5,00 & 5,00 & 5,00 \\
\hline Calcário calcítico & 4,50 & 4,50 & 4,40 & 4,45 & 4,50 & 4,50 & 4,45 & 4,45 \\
\hline Fosfato bicálcico & 1,17 & 1,17 & 1,30 & 1,20 & 1,17 & 1,17 & 1,20 & 1,20 \\
\hline $\mathrm{BHT}^{3}$ & 0,20 & 0,20 & 0,20 & 0,20 & 0,20 & 0,20 & 0,20 & 0,20 \\
\hline DL- metionina & 0,37 & 0,37 & 0,38 & 0,38 & 0,37 & 0,37 & 0,38 & 0,38 \\
\hline L- lisina & 0,11 & 0,11 & 0,09 & 0,09 & 0,12 & 0,11 & 0,09 & 0,09 \\
\hline Óleo ácido & 4,00 & 4,00 & 8,00 & 8,00 & - & - & - & - \\
\hline Óleo degomado & - & - & - & - & 4,00 & 4,00 & 8,00 & 8,00 \\
\hline Lecitina & - & 1,00 & - & 1,00 & - & 1,00 & - & 1,00 \\
\hline Total (kg) & 100 & 100 & 100 & 100 & 100 & 100 & 100 & 100 \\
\hline \multicolumn{9}{|c|}{ Composição química (calculada sobre a dieta total) } \\
\hline EM (kcal/kg) & \multicolumn{8}{|c|}{2,800} \\
\hline Proteína bruta (\%) & \multicolumn{8}{|c|}{20,00} \\
\hline Cálcio (\%) & 3,10 & 3,10 & 3,09 & 3,09 & 3,10 & 3,10 & 3,09 & 3,09 \\
\hline Cloro (\%) & 0,04 & 0,04 & 0,03 & 0,03 & 0,04 & 0,04 & 0,03 & 0,03 \\
\hline Fósforo disponível (\%) & 0,32 & 0,33 & 0,32 & 0,33 & 0,32 & 0,33 & 0,32 & 0,33 \\
\hline Metionina+Cistina digestível (\%) & 0,88 & 0,88 & 0,88 & 0,88 & 0,88 & 0,88 & 0,88 & 0,88 \\
\hline Lisina digestível (\%) & 1,08 & 1,08 & 1,10 & 1,10 & 1,09 & 1,09 & 1,10 & 1,10 \\
\hline Treonina digestível (\%) & 0,67 & 0,67 & 0,67 & 0,67 & 0,67 & 0,67 & 0,67 & 0,67 \\
\hline Potássio (\%) & 0,77 & 0,77 & 0,78 & 0,78 & 0,77 & 0,77 & 0,78 & 0,78 \\
\hline Sódio (\%) & 0,19 & 0,19 & 0,19 & 0,19 & 0,19 & 0,19 & 0,19 & 0,19 \\
\hline
\end{tabular}

${ }^{1}$ Areia fina; ${ }^{2}$ Níveis de garantia por quilo de produto: núcleo postura: Vitamina A (UI) 207000; Vitamina $\mathrm{D}_{3}$ (UI) 43200; Vitamina $\mathrm{E}$ (mg) 540; Vitamina $\mathrm{K}_{3}$ (mg) 51,5; Vitamina $\mathrm{B}_{1}$ (mg) 40; Vitamina $\mathrm{B}_{2}$ (mg) 120; Vitamina $\mathrm{B}_{6}$ (mg) 54; Vitamina $\mathrm{B}_{12}$ (mcg) 430; Niacina (mg) 840; Ácido Fólico (mg) 16,7; Ácido Pantotênico (mg) 204,6; Colina (mg) 42; Biotina (mg) 1,4; Metionina (g) 11; Manganês (mg) 1485; Zinco (mg) 1535; Ferro (mg) 1695; Cobre (mg) 244; lodo (mg) 29; Selênio (mg) 3,2; Bacitracina de zinco (mg) 600; BHT (mg) 700; Cálcio (g) 197,5; Cobalto (mg) 5,1; Flúor (máximo) (mg) 400; Fósforo (g) 50; Sódio (g) 36; ${ }^{3}$ Hidroxitolueno butilado; ${ }^{4}$ Tratamentos: T1: $4 \%$ óleo ácido de soja; T2: $4 \%$ óleo ácido de soja+1\% lecitina; T3: 8\% óleo ácido de soja; T4: 8\% óleo ácido de soja+1\% lecitina; T5: 4\% óleo degomado de soja; T6: 4\% óleo degomado de soja+1\% lecitina; T7: 8\% óleo degomado de soja; T8: 8\% óleo degomado de soja+1\% lecitina.

Para a determinação da acidez e dos coeficientes de extinção, foi realizada a extração da fração lipídica das dietas, de acordo com AACC (1995). A acidez titulável foi expressa como a quantidade de miligramas de hidróxido de sódio necessária para neutralizar os ácidos em $100 \mathrm{~g}$ de amostra, utilizando-se uma solução de fenolftaleína como indicador, de acordo com o procedimento descrito no método AACC 02-01 (AACC, 2000).

Os coeficientes de extinção específica ( $K$ e $K$ ) foram determinados utilizando-se balão volumétrico de $10 \mathrm{~mL}$; foi pesado 0,1 g de óleo (limpo e filtrado), sendo o volume completado com iso-octano de grau HPLC, sendo a solução medida usando-se um espectrofotômetro (Jenway, 6705 UV/Vis) a 232 e 270 nm. As absorbâncias foram usadas para determinar os coeficientes de extinção específicos ( $K$ e $K$ ), empregando-se o método proposto pela American Oil Chemists Society's (FIRESTONE, 2001).

\subsection{Análise estatística}

Foi realizada a análise de medidas repetidas usando-se o pacote "nlme - Linear and Nonlinear Mixed Effects Models" do pacote estatístico R (R CORE TEAM, 2015), de acordo com o seguinte Modelo 1 :

$$
\text { Yijk }=\mu+d i+w k+d w j k+e i j k
$$

em que: $\mu=$ média geral; di = efeito fixo da dieta $(i=1$ a 8 dietas); $w k=$ efeito fixo do tempo de armazenamento ( $k=1$ a 3$) ; d w j k$ = interação entre dieta e tempo de armazenamento (tratamento $\times$ tempo); eijk = erro aleatório (erro residual).

A interação dieta $\times$ tempo de armazenamento foi considerada efeito fixo. Após realizar ANOVA, foi utilizado o procedimento "LSM - least squares means", sendo as médias comparadas através do teste Tukey com um nível de significância $p<0,05$. 
Coprodutos do óleo de soja na dieta de codornas: impactos sobre a qualidade durante o armazenamento

Bavaresco, C. et al.

\section{Resultados e discussão}

Na Tabela 2, são apresentados os dados de matéria seca das dietas armazenadas durante diferentes períodos. Avaliando-se o efeito do tempo de armazenamento, as dietas com 4\% de OAS sem ou com LEC (tratamentos 3 e 4) e a dieta com 4\% ODS (tratamento 5) apresentaram menor conteúdo de matéria seca no início do armazenamento, em relação aos 15 dias e 30 dias, respectivamente. Avaliando-se o efeito de tratamento, foram encontradas diferenças significativas entre 4\% OAS e 4\% OAS+LEC (dietas 1 e 2), que apresentaram as menores médias em relação ao tratamento 8 ( $8 \%$ ODS+LEC), o qual obteve maior valor de matéria seca.
As diferenças observadas na quantidade de matéria seca, durante o período de armazenamento, possivelmente podem ser explicadas pela dessorção que ocorre quando a pressão de vapor dos grãos é maior do que a pressão do ar circundante ou pela sorção, que é quando a pressão de vapor dos grãos (no presente estudo, mais especificamente dos ingredientes da dieta) for menor que a pressão do ar circundante, pois os mesmos tendem sempre a entrar em equilíbrio higroscópico com o ar que os circunda (SUN; WOODS, 1994).

As dietas foram formuladas para atenderem aos critérios de serem isoenergéticas e isoproteicas, a fim de manter a mesma quantidade de energia metabolizável e proteína bruta; portanto, a ausência de diferença

Tabela 2. Porcentagem de matéria seca de dietas formuladas com óleo ácido e degomado de soja com ou sem lecitina, e armazenadas por até 30 dias.

\begin{tabular}{|c|c|c|c|}
\hline \multirow{2}{*}{ Dietas $^{1}$} & \multicolumn{3}{|c|}{ Tempo de armazenamento (dias) ${ }^{*}$} \\
\hline & 0 & 15 & 30 \\
\hline 1 & a $89,31 \pm 0,74 B$ & a $89,48 \pm 0,78 \mathrm{C}$ & a $89,57 \pm 0,46 B$ \\
\hline 2 & a $89,36 \pm 0,52 A B$ & a $89,63 \pm 0,47 \mathrm{BC}$ & a $89,66 \pm 0,16 \mathrm{AB}$ \\
\hline 3 & b $89,93 \pm 0,47 A B$ & a $90,51 \pm 0,41 \mathrm{ABC}$ & a $90,56 \pm 0,40 A B$ \\
\hline 4 & b $90,07 \pm 0,62 A B$ & a $90,84 \pm 0,47 \mathrm{ABC}$ & $a b 90,59 \pm 0,34 A B$ \\
\hline 5 & b $89,41 \pm 0,76 \mathrm{AB}$ & a $90,08 \pm 0,69 A B C$ & $a b 89,74 \pm 0,59 A B$ \\
\hline 6 & a $89,60 \pm 0,69 A B$ & a $90,10 \pm 0,50 \mathrm{ABC}$ & a $90,08 \pm 0,88 A B$ \\
\hline 7 & a $90,58 \pm 0,52 \mathrm{AB}$ & a $91,01 \pm 0,55 \mathrm{AB}$ & a $90,91 \pm 0,24 \mathrm{AB}$ \\
\hline 8 & a $90,84 \pm 0,53 \mathrm{~A}$ & a $91,17 \pm 0,64 \mathrm{~A}$ & a $91,09 \pm 0,41 \mathrm{~A}$ \\
\hline Efeitos & \multicolumn{3}{|c|}{ Probabilidade $(p \leq 0,05)$} \\
\hline Dietas (D) & \multicolumn{3}{|c|}{0,0025} \\
\hline Tempo (T) & \multicolumn{3}{|c|}{$<0,0001$} \\
\hline Interação D×T* & \multicolumn{3}{|c|}{0,9048} \\
\hline
\end{tabular}

1Dietas: 1) 4\% óleo ácido de soja; 2) 4\% óleo ácido de soja+1\% lecitina; 3) 8\% óleo ácido de soja; 4) 8\% óleo ácido de soja+1\% lecitina; 5) $4 \%$ óleo degomado de soja; 6) $4 \%$ óleo degomado de soja+1\% lecitina; 7 ) 8\% óleo degomado de soja; 8 ) $8 \%$ óleo degomado de soja+1\% lecitina; *Médias aritméticas simples de seis repetições \pm desvio padrão, seguidas por diferentes letras maiúsculas na mesma coluna (efeito da dieta) e precedidas por minúsculas na mesma linha (efeito do tempo de armazenamento), diferem entre si pelo teste de Tukey ( $p \leq 0,05)$.

Tabela 3. Porcentagem de proteína bruta de dietas formuladas com óleo ácido e degomado de soja com ou sem lecitina, e armazenadas por até 30 dias.

\begin{tabular}{cccc} 
Dietas $^{1}$ & \multicolumn{3}{c}{ Tempo de armazenamento (dias) } \\
\cline { 2 - 4 } 1 & $\mathbf{0}$ & $\mathbf{1 5}$ & $\mathbf{3 0}$ \\
2 & $20,00 \pm 1,68$ & $20,39 \pm 0,36$ & $19,35 \pm 0,45$ \\
3 & $19,16 \pm 0,28$ & $18,64 \pm 2,13$ & $19,75 \pm 0,36$ \\
4 & $19,39 \pm 1,96$ & $20,83 \pm 0,87$ & $19,77 \pm 2,36$ \\
5 & $20,41 \pm 1,08$ & $19,59 \pm 0,51$ & $19,89 \pm 0,92$ \\
6 & $19,87 \pm 0,75$ & $21,18 \pm 2,62$ & $18,88 \pm 1,11$ \\
7 & $18,98 \pm 1,29$ & $20,12 \pm 2,97$ & $19,97 \pm 3,06$ \\
8 & $21,31 \pm 1,59$ & $19,26 \pm 2,27$ & $20,30 \pm 0,82$ \\
Efeitos & $20,54 \pm 0,40$ & $21,66 \pm 1,70$ & \\
Dietas (D) & & Probabilidade $(p \leq 0,05)$ & 0,7767 \\
Tempo (T) & & 0,5028 & 0,6919 \\
Interação DxT & & 0
\end{tabular}

${ }^{1}$ Dietas: 1) 4\% óleo ácido de soja; 2) 4\% óleo ácido de soja+1\% lecitina; 3) 8\% óleo ácido de soja; 4) 8\% óleo ácido de soja+1\% lecitina; 5) 4\% óleo degomado de soja; 6) 4\% óleo degomado de soja+1\% lecitina; 7) 8\% óleo degomado de soja; 8) 8\% óleo degomado de soja+1\% lecitina. 
estatística entre tratamentos já era esperada (Tabela 3). Contudo, mudanças no conteúdo de proteína eram esperadas durante o período de armazenamento, devido a relatos de alguns autores, como Chen et al. (2011) e Stanojevic et al. (2011), que afirmaram a ocorrência de desnaturação proteica durante o armazenamento de grãos. Este fenômeno sugere que as proteínas podem ser degradadas em pequenos peptídeos e aminoácidos, com o passar do tempo. Entretanto, no presente trabalho, não foi observada redução na quantidade de proteína em nenhuma das dietas durante 30 dias de armazenamento (Tabela 3), podendo sugerir que as condições e o tempo de armazenamento aos quais as dietas foram submetidas não proporcionaram uma condição ideal para a degradação proteica que resultasse em redução do seu conteúdo.

Conforme pode ser observado na Tabela 4, não houve efeito do tempo de armazenamento sobre o extrato etéreo, sendo encontradas diferenças significativas apenas na comparação entre as dietas. As diferenças encontradas entre os tratamentos se repetem nos períodos avaliados de zero e 15 dias, em que o tratamento 4 (8\% OAS+LEC) apresenta maior conteúdo de gordura do que o tratamento 1 (4\% OAS), resultado esperado devido a diferentes quantidades de óleo utilizado nas dietas, além da contribuição da LEC no tratamento 4, que possui alta quantidade de gordura $(92,76 \%)$, segundo (ROSTAGNO et al., 2011).

Em trabalho realizado por Gopinger et al. (2015), com farelo de arroz integral estocado até 120 dias, tratado ou não com ácidos orgânicos, foi verificada a redução do conteúdo de EE a partir dos 90 dias de armazenamento no farelo não tratado; entretanto, no presente estudo, o tempo de armazenamento máximo avaliado foi de 30 dias, podendo sugerir que as rações deveriam ser submetidas a um maior tempo de estocagem, para ocorrer alguma variação do conteúdo de gordura das dietas.

A degradação dos lipídios durante o armazenamento ocorre em virtude dos processos bioquímicos, como a respiração, ou processos de oxidação, que podem ser ocasionados por enzimas lipases, fosfolipases e as peroxidases presentes nas próprias amostras ou estarem associadas à microflora agregada (RUPOLLO et al., 2004).

A prática do uso de antioxidantes nas rações de aves é algo comum e o mecanismo de ação dessas substâncias protege as gorduras da oxidação, conservando, assim, a qualidade nutricional dos alimentos, fazendo com que se evitem perdas de alta significância (AMARAL NETO, 1999). No presente estudo, utilizou-se o hidroxitolueno butilado (BHT) em todas as dietas experimentais; este fato pode estar associado com os resultados encontrados, que apontam que o armazenamento da ração por até 30 dias não foi suficiente para alterar o conteúdo de EE.

$\mathrm{Na}$ Tabela 5, são apresentados os dados de acidez lipídica das dietas. Foi possível observar interação significativa entre dietas e tempo de armazenamento $(p<0,0001)$. Como esperado, as dietas com OAS apresentaram maior acidez do que as dietas com ODS. Este fato está relacionado com os valores maiores de acidez em ácido oleico $(64,68 \%)$ obtidos no OAS, em comparação ao ODS, que apresentava apenas 0,28\% de acidez na matéria-prima original. Porém, é possível observar que a lecitina se comporta de maneira diferente dependendo do óleo associado a ela. Na presença de OAS com a suplementação de LEC, observaram-se inicialmente valores maiores de acidez, que se reduziram ao longo do tempo de armazenamento, o que não aconteceu na ausência de

Tabela 4. Porcentagem de extrato etéreo de dietas formuladas com óleo ácido e degomado de soja com ou sem lecitina, e armazenadas por até 30 dias.

\begin{tabular}{cccc} 
Dietas $^{1}$ & \multicolumn{3}{c}{ Tempo de armazenamento (dias) } \\
\cline { 2 - 4 } 1 & $\mathbf{0}$ & $\mathbf{1 5}$ & $\mathbf{3 0}$ \\
2 & $6,29 \pm 0,11 \mathrm{~B}$ & $7,16 \pm 1,31 \mathrm{AB}$ & $7,34 \pm 0,71$ \\
3 & $7,79 \pm 0,27 \mathrm{AB}$ & $7,24 \pm 0,21 \mathrm{AB}$ & $7,72 \pm 0,64$ \\
4 & $10,33 \pm 3,16 \mathrm{AB}$ & $9,52 \pm 2,69 \mathrm{AB}$ & $9,21 \pm 2,28$ \\
5 & $11,54 \pm 1,47 \mathrm{~A}$ & $10,95 \pm 0,70 \mathrm{~A}$ & $10,61 \pm 0,28$ \\
6 & $7,28 \pm 0,27 \mathrm{~B}$ & $6,73 \pm 0,20 \mathrm{~B}$ & $6,79 \pm 0,33$ \\
7 & $7,99 \pm 0,50 \mathrm{AB}$ & $7,98 \pm 0,51 \mathrm{AB}$ & $8,26 \pm 0,57$ \\
8 & $9,21 \pm 1,79 \mathrm{AB}$ & $9,43 \pm 2,66 \mathrm{AB}$ & $9,57 \pm 2,49$ \\
Efeitos & $10,16 \pm 2,02 \mathrm{AB}$ & $10,35 \pm 2,69 \mathrm{AB}$ & $10,87 \pm 2,22$ \\
Dietas (D) & & Probabilidade $(p \leq 0,05)$ & \\
Tempo (T) & & $<0,0001$ & 0,7677 \\
Interação DxT* & & 0,6133 & \\
\hline
\end{tabular}

${ }^{1}$ Dietas: 1) 4\% óleo ácido de soja; 2) 4\% óleo ácido de soja+1\% lecitina; 3) 8\% óleo ácido de soja; 4) 8\% óleo ácido de soja+1\% lecitina; 5) 4\% óleo degomado de soja; 6) 4\% óleo degomado de soja+1\% lecitina; 7) 8\% óleo degomado de soja; 8) 8\% óleo degomado de soja+1\% lecitina; *Médias aritméticas simples de seis repetições \pm desvio padrão, seguidas por diferentes letras maiúsculas na mesma coluna (efeito da dieta), diferem entre si pelo teste de Tukey $(p \leq 0,05)$. 
Tabela 5. Acidez lipídica (mg de NaOH.100 g-1 de óleo) de dietas formuladas com óleo ácido e degomado de soja com ou sem lecitina, e armazenadas por até 30 dias.

\begin{tabular}{|c|c|c|c|}
\hline \multirow{2}{*}{ Dietas $^{1}$} & \multicolumn{3}{|c|}{ Tempo de armazenamento (dias) } \\
\hline & 0 & 15 & 30 \\
\hline 1 & $a b 4,26 \pm 0,26 C$ & a $4,40 \pm 0,51 \mathrm{~B}$ & b $4,11 \pm 0,14 \mathrm{~B}$ \\
\hline 2 & a $4,63 \pm 0,43 \mathrm{C}$ & b $4,31 \pm 0,29 B$ & $a b 4,39 \pm 0,31 B$ \\
\hline 3 & b $7,13 \pm 0,30 B$ & b $7,17 \pm 0,63 \mathrm{~A}$ & a $7,46 \pm 0,75 \mathrm{~A}$ \\
\hline 4 & a $7,61 \pm 0,53 \mathrm{~A}$ & b $7,12 \pm 0,40 \mathrm{~A}$ & a $7,47 \pm 0,45 \mathrm{~A}$ \\
\hline 5 & a $0,90 \pm 0,10 \mathrm{D}$ & a $1,06 \pm 0,09 \mathrm{C}$ & a $1,08 \pm 0,09 \mathrm{C}$ \\
\hline 6 & a $1,09 \pm 0,17 \mathrm{D}$ & a $1,07 \pm 0,11 \mathrm{C}$ & a $1,31 \pm 0,20 \mathrm{C}$ \\
\hline 7 & a $1,16 \pm 0,40 \mathrm{D}$ & b $0,86 \pm 0,07 C$ & $a b 1,10 \pm 0,12 C$ \\
\hline 8 & b $0,99 \pm 0,13 \mathrm{D}$ & b $1,14 \pm 0,17 \mathrm{C}$ & a $1,42 \pm 0,22 \mathrm{C}$ \\
\hline Efeitos & \multicolumn{3}{|c|}{ Probabilidade $(p \leq 0,05)$} \\
\hline Dietas (D) & \multicolumn{3}{|c|}{$<0,0001$} \\
\hline Tempo (T) & \multicolumn{3}{|c|}{0,0011} \\
\hline Interação $\mathrm{D} \times \mathrm{T}^{\star}$ & \multicolumn{3}{|c|}{$<0,0001$} \\
\hline
\end{tabular}

${ }^{1}$ Dietas: 1) 4\% óleo ácido de soja; 2) 4\% óleo ácido de soja+1\% lecitina; 3) 8\% óleo ácido de soja; 4) 8\% óleo ácido de soja+1\% lecitina; 5) 4\% óleo degomado de soja; 6) 4\% óleo degomado de soja+1\% lecitina; 7) 8\% óleo degomado de soja; 8) 8\% óleo degomado de soja+1\% lecitina; *Médias aritméticas simples de seis repetições \pm desvio padrão, seguidas por diferentes letras maiúsculas na mesma coluna (efeito da dieta) e precedidas por minúsculas na mesma linha (efeito do tempo de armazenamento), diferem entre si pelo teste de Tukey $(p \leq 0,05)$.

LEC. Ao contrário, na dieta com ODS (T8), os resultados de acidez aumentaram durante o armazenamento, com a presença de LEC.

Na Tabela 6, são apresentados os dados da avaliação do coeficiente de extinção específico a $232 \mathrm{~nm}$ $(K)$, em que foi observada a interação significativa entre tratamento e tempo $(p<0,0001)$. Essa propriedade dá um indicativo da presença de peróxidos, hidroperóxidos e dienos conjugados, que são produtos primários da oxidação (CLODOVEO et al., 2007). As dietas contendo OAS apresentaram as maiores médias do $K$ nas avaliações dos tempos zero e 15 dias.

Dietas contendo OAS desde o tempo zero já apresentaram médias superiores de $K$, em relação aos tratamentos com ODS. O OAS possui grandes quantidades de ácidos graxos na forma livre, os quais possuem maior susceptibilidade à oxidação, acarretando aumento de reações de oxidação nas dietas já no período inicial do armazenamento. Assim, trata-se de um subproduto da indústria do óleo de soja com alto nível de acidez livre, indicando grandes quantidades de substrato susceptíveis às reações de degradação (RODRIGUES et al., 2012).

A avaliação do coeficiente de extinção especifico a $270 \mathrm{~nm}(K)$ está relacionada com a presença de compostos secundários de oxidação, tais como cetonas, aldeídos e álcoois (RODRIGUES et al., 2012). Os dados dessa propriedade são apresentados na Tabela 7, na qual se observa interação entre tratamento e tempo de armazenamento $(p<0,0001)$. Independentemente do tempo de armazenamento avaliado, observou-se que as dietas com OAS apresentaram as maiores médias de $K$, corroborando com o que foi discutido anteriormente: - OAS, por apresentar maior quantidade de ácidos graxos livres, possui maior concentração de substrato para a ocorrência de reações de degradação. Apesar desta constatação, poucas variações foram observadas entre os tempos de armazenamento estudados, indicando novamente que o OAS, já no momento de sua inclusão nas dietas, apresentava grandes quantidades de produtos primários $(K)$ e secundários $(K)$ de oxidação.

Apesar de a oxidação ser um resultado natural dos processos metabólicos, a formação excessiva de espécies reativas, como radicais livres, pode danificar importantes biomoléculas (lipídios, proteínas, ácidos nucleicos) tanto no organismo humano quanto animal (DELLES et al., 2014). Segundo Smet et al. (2008), a taxa de oxidação é aumentada de acordo com alguns fatores, como: (1) aumento do consumo de lipídios oxidados e pró-oxidantes; (2) deterioração de ácidos graxos poli-insaturados (PUFAS); (3) baixo consumo de nutrientes antioxidantes. Desta maneira, evitar que reações de oxidação ocorram é impossível; entretanto, principalmente quando se utilizam coprodutos na formulação de dietas para aves, deve haver preocupação com a qualidade do produto final, já que geralmente esses ingredientes possuem qualidade inferior.

A variação da qualidade dos coprodutos do refino do óleo de soja é influenciada por diversos fatores, inclusive pelos diferentes processamentos adotados pelas indústrias, uma vez que estes, muitas vezes, não são padronizados. $O$ procedimento ideal, dessa forma, seria adquirir esses produtos do mesmo fornecedor, para reduzir a variação na qualidade do ingrediente em questão. 
Coprodutos do óleo de soja na dieta de codornas: impactos sobre a qualidade durante o armazenamento Bavaresco, C. et al.

Tabela 6. Coeficiente de extinção específico a $232 \mathrm{~nm}(K)$ de dietas formuladas com óleo ácido e degomado de soja com ou sem lecitina, armazenadas por até 30 dias.

\begin{tabular}{|c|c|c|c|}
\hline \multirow{2}{*}{ Dietas $^{1}$} & \multicolumn{3}{|c|}{ Tempo de armazenamento (dias) } \\
\hline & 0 & 15 & 30 \\
\hline 1 & a $13,68 \pm 0,95 A$ & $a b 12,68 \pm 0,97 A$ & b $12,01 \pm 1,15 \mathrm{AB}$ \\
\hline 2 & a $12,78 \pm 0,82 \mathrm{~A}$ & ab $11,77 \pm 1,27 \mathrm{~A}$ & b $11,65 \pm 0,96 \mathrm{AB}$ \\
\hline 3 & ab $12,48 \pm 0,49 A$ & b $11,79 \pm 0,49 A$ & a $12,95 \pm 1,15 \mathrm{~A}$ \\
\hline 4 & a $12,62 \pm 0,82 \mathrm{~A}$ & a $12,58 \pm 1,04 \mathrm{~A}$ & a $12,38 \pm 0,73 \mathrm{~A}$ \\
\hline 5 & a $9,19 \pm 0,66 \mathrm{~B}$ & a $8,84 \pm 0,49 \mathrm{~B}$ & a $8,90 \pm 0,60 \mathrm{C}$ \\
\hline 6 & b $7,99 \pm 0,50 \mathrm{BC}$ & b $8,14 \pm 0,38 \mathrm{BC}$ & a $10,72 \pm 0,51 \mathrm{~B}$ \\
\hline 7 & a $7,63 \pm 0,68 \mathrm{C}$ & a $6,96 \pm 0,59 \mathrm{C}$ & a $6,80 \pm 0,76 \mathrm{D}$ \\
\hline 8 & a $6,88 \pm 0,77 \mathrm{C}$ & a $6,93 \pm 0,85 \mathrm{C}$ & a $6,87 \pm 0,74 \mathrm{D}$ \\
\hline Efeitos & \multicolumn{3}{|c|}{ Probabilidade $(p \leq 0,05)$} \\
\hline Dietas (D) & \multicolumn{3}{|c|}{$<0,0001$} \\
\hline Tempo (T) & \multicolumn{3}{|c|}{0,0143} \\
\hline Interação $\mathrm{D} \times \mathrm{T}^{\star}$ & \multicolumn{3}{|c|}{$<0,0001$} \\
\hline
\end{tabular}

${ }^{1}$ Dietas: 1) 4\% óleo ácido de soja; 2) 4\% óleo ácido de soja+1\% lecitina; 3) 8\% óleo ácido de soja; 4) 8\% óleo ácido de soja+1\% lecitina; 5) 4\% óleo degomado de soja; 6) 4\% óleo degomado de soja+1\% lecitina; 7) 8\% óleo degomado de soja; 8) 8\% óleo degomado de soja+1\% lecitina; *Médias aritméticas simples de seis repetições \pm desvio padrão, seguidas por diferentes letras maiúsculas na mesma coluna (efeito da dieta) e precedidas por minúsculas na mesma linha (efeito do tempo de armazenamento), diferem entre si pelo teste de Tukey $(p \leq 0,05)$.

Tabela 7. Coeficiente de extinção K de dietas formuladas com óleo ácido e degomado de soja com ou sem lecitina, armazenadas por até 30 dias.

\begin{tabular}{|c|c|c|c|}
\hline \multirow{2}{*}{ Dietas $^{1}$} & \multicolumn{3}{|c|}{ Tempo de armazenamento (dias) } \\
\hline & 0 & 15 & 30 \\
\hline 1 & a $6,27 \pm 0,78 \mathrm{~A}$ & a $6,32 \pm 0,60 \mathrm{~A}$ & a $6,43 \pm 0,26 \mathrm{~A}$ \\
\hline 2 & a $5,86 \pm 0,30 \mathrm{~A}$ & a $5,84 \pm 0,38 \mathrm{~A}$ & a $6,07 \pm 0,47 \mathrm{~A}$ \\
\hline 3 & $a b 6,06 \pm 0,57 \mathrm{~A}$ & a $6,40 \pm 0,57 \mathrm{~A}$ & b $5,88 \pm 0,44 \mathrm{~A}$ \\
\hline 4 & a $5,74 \pm 0,26 \mathrm{~A}$ & a $6,04 \pm 0,39 \mathrm{~A}$ & a $5,73 \pm 0,51 \mathrm{~A}$ \\
\hline 5 & a 2,42 $\pm 0,34 \mathrm{~B}$ & a $2,51 \pm 0,22 \mathrm{BC}$ & a $2,61 \pm 0,16 \mathrm{C}$ \\
\hline 6 & b 2,44 $\pm 0,18 B$ & b $2,65 \pm 0,26 B$ & a $4,30 \pm 0,49 B$ \\
\hline 7 & a $1,98 \pm 0,34 B$ & a $1,77 \pm 0,31 \mathrm{D}$ & a $1,90 \pm 0,30 \mathrm{C}$ \\
\hline 8 & a $1,78 \pm 0,36 \mathrm{~B}$ & a $1,84 \pm 0,38 \mathrm{CD}$ & a $1,91 \pm 0,29 \mathrm{C}$ \\
\hline Efeitos & \multicolumn{3}{|c|}{ Probabilidade $(p \leq 0,05)$} \\
\hline Dietas (D) & \multicolumn{3}{|c|}{$<0,0001$} \\
\hline Tempo (T) & \multicolumn{3}{|c|}{$<0,0001$} \\
\hline Interação D×T* & \multicolumn{3}{|c|}{$<0,0001$} \\
\hline
\end{tabular}

${ }^{1}$ Dietas: 1) 4\% óleo ácido de soja; 2) 4\% óleo ácido de soja+1\% lecitina; 3) 8\% óleo ácido de soja; 4) 8\% óleo ácido de soja+1\% lecitina; 5) 4\% óleo degomado de soja; 6) 4\% óleo degomado de soja+1\% lecitina; 7) 8\% óleo degomado de soja; 8) 8\% óleo degomado de soja+1\% lecitina; *Médias aritméticas simples de seis repetições \pm desvio padrão, seguidas por diferentes letras maiúsculas na mesma coluna (efeito da dieta) e precedidas por minúsculas na mesma linha (efeito do tempo de armazenamento), diferem entre si pelo teste de Tukey ( $p \leq 0,05)$.

\section{Conclusões}

A eficiência da lecitina sobre a qualidade das dietas não ficou evidente, sendo que os tratamentos com óleo degomado de soja apresentaram valores reduzidos de acidez e coeficientes de extinção, demonstrando maior qualidade desse óleo. No entanto, o uso do óleo ácido de soja, apesar de aumentar a concentração de produtos primários e secundários da oxidação, pode ser considerado na alimentação de codornas, já que não ocorreram perdas quantitativas de proteína e gordura bruta durante o armazenamento de dietas por até 30 dias.

\section{Agradecimentos}

Este estudo é parte do projeto de pesquisa apoiado pela FAPERGS (Edital 02/2014 - PqG) e MCTI/CNPq (Edital 14/2014). O óleo ácido e degomado, e a lecitina de soja, utilizados nesta pesquisa, foram fornecidos pela Empresa Sulina Óleos.

\section{Referências}

AMARAL NETO, E. B. A. Antioxidantes na conservação das características nutricionais de alimentos usados em rações para 
Coprodutos do óleo de soja na dieta de codornas: impactos sobre a qualidade durante o armazenamento Bavaresco, C. et al.

aves. 1999. 72 f. Tese (Doutorado em Zootecnia)--Departamento de Zootecnia, Universidade Federal de Viçosa, Viçosa, 1999.

AMERICAN ASSOCIATION OF CEREAL CHEMISTS - AACC. Approved methods of the AACC. St. Paul: AACC, 1995.

AMERICAN ASSOCIATION OF CEREAL CHEMISTS - AACC. Approved methods of the AACC. 10th ed. St. Paul: AACC 2000. p. 46-13.

ASSOCIAÇÃO BRASILEIRA DAS INDÚSTRIAS DE ÓLEOS VEGETAIS - ABIOVE. Coordenadoria de Economia e Estatística. Balanço de oferta e demanda. São Paulo: ABIOVE, 2016.

CHEN, L.; CHEN, J.; REN, J.; ZHAO, M. Effects of ultrasound pretreatment on the enzymatic hydrolysis of soy protein isolates and on the emulsifying properties of hydrolysates. Journal of Agricultural and Food Chemistry, v. 59, n. 6, p. 2600-2609, 2011. PMid:21329351. http://dx.doi.org/10.1021/jf103771x.

CLODOVEO, M. L.; DELCURATOLO, D.; GOMES, T.; COLELLI, G. Effect of different temperatures and storage atmospheres on Coratina olive oil quality. Food Chemistry, v. 102, n. 3, p. 571-576, 2007. http://dx.doi.org/10.1016/j.foodchem.2006.05.035.

DELLES, R. M.; XIONG, Y. L.; TRUE, A. D.; AO, T.; DAWSON, K. A. Dietary antioxidant supplementation enhances lipid and protein oxidative stability of chicken broiler meat through promotion of antioxidant enzyme activity. Poultry Science, v. 93, n. 6, p. 1561-1570, 2014. PMid:24879706. http://dx.doi.org/10.3382/ ps.2013-03682.

FIRESTONE, D. (Ed.). Official methods and recommended practices of the AOCS. 6th ed. Champaign: AOCS, 2001.

GOPINGER, E.; ZIEGLER, V.; CATALAN, A. A. S.; KRABBE, E. L.; ELIAS, M. C.; XAVIER, E. G. Whole rice bran stabilization using a short chain organic acid mixture. Journal of Stored Products Research, v. 61, p. 108-113, 2015. http://dx.doi.org/10.1016/j. jspr.2015.01.003.

HORWITZ, W. (Ed.). Official methods of analysis of AOAC International. Washington: AOAC, 2006.

MANDARINO, J. M. G.; HIRAKURI, M. H.; ROESSING, A. C. Tecnologia para produção do óleo de soja: descrição das etapas, equipamentos, produtos e subprodutos. 2. ed. Londrina: Embrapa, 2015. p. 43.

NAZ, S.; SHEIKH, H.; SIDDIQI, R.; SAYEED, S. A. Oxidative stability of olive, corn and soybean oil under different conditions.
Food Chemistry, v. 88, n. 2, p. 253-259, 2004. http://dx.doi. org/10.1016/j.foodchem.2004.01.042.

R CORE TEAM. R: a language and environment for statistical computing. Vienna: R Foundation for Statistical Computing, 2015.

RABER, M.; RIBEIRO, A.; KESSLER, A.; ARNAIZ, V. Suplementação de glicerol ou de lecitina em diferentes níveis de ácidos graxos livres em dietas para frangos de corte. Ciência Animal Brasileira, v. 10, n. 3, p. 745-753, 2009.

RODRIGUES, N.; MALHEIRO, R.; CASAL, S.; ASENSIO-SMANZANERA, M. C.; BENTO, A.; PEREIRA, J. A. Influence of spike lavender (Lavandula latifolia Med.) essential oil in the quality, stability and composition of soybean oil during microwave heating. Food and Chemical Toxicology, v. 50, n. 8, p. 2894-2901, 2012. PMid:22659463. http://dx.doi.org/10.1016/j.fct.2012.05.020

ROSTAGNO, H. S.; ALBINO, L. F. T.; DONZELE, J. L.; GOMES, P. C.; OLIVEIRA, R. F.; LOPES, D. C.; FERREIRA, A. S.; BARRETO, S. L. T.; EUCLIDES, R. F. Tabelas brasileiras para aves e suínos: composição de alimentos e exigências nutricionais. 3. ed. Viçosa: UFV, 2011. 252 p.

RUPOLLO, G.; GUTKOSKI, L. C.; MARINI, L. J.; ELIAS, M. C. Sistemas de armazenamento hermético e convencional na conservabilidade de grãos de aveia. Ciência Rural, v. 34, n. 6, p. 1715-1722, 2004. http://dx.doi.org/10.1590/S010384782004000600008 .

SINDICATO NACIONAL DA INDÚSTRIA DE ALIMENTAÇÃO ANIMAL - SINDIRAÇÕES. Compêndio brasileiro de alimentação animal. São Paulo: SINDIRAÇÕES. 2005. v. 62.

SMET, K.; RAES, K.; HUYGHEBAERT, G.; HAAK, L.; ARNOUTS, S.; DE SMET, S. Lipid and protein oxidation of broiler meat as influenced by dietary natural antioxidant supplementation. Poultry Science, v. 87, n. 8, p. 1682-1688, 2008. PMid:18648067. http:// dx.doi.org/10.3382/ps.2007-00384.

STANOJEVIC, S. P.; BARAC, M. B.; PESIC, M. B.; VUCELICRADOVIC, B. V. Assessment of soy genotype and processing method on quality of soybean tofu. Journal of Agricultural and Food Chemistry, v. 59, n. 13, p. 7368-7376, 2011. PMid:21627319. http://dx.doi.org/10.1021/jf2006672.

SUN, D.; WOODS, J. L. Low temperature moisture transfer characteristics of barley: thin-layer models and equilibrium isotherms. Journal of Agricultural Engineering Research, v. 59, n. 4, p. 273-283, 1994. http://dx.doi.org/10.1006/jaer.1994.1086. 